\title{
Investigation of Transmission Warming Technologies at Various Ambient Conditions
}

\section{Forrest Jehlik and Simeon Iliev}

Argonne National Laboratory

\section{Eric Wood and Jeff Gonder}

National Renewable Energy Laboratory

CITATION: Jehlik, F., Iliev, S., Wood, E., and Gonder , J., "Investigation of Transmission Warming Technologies at Various Ambient Conditions," SAE Technical Paper 2017-01-0157, 2017, doi:10.4271/2017-01-0157.

Copyright (C) 2017 SAE International

\begin{abstract}
This work details two approaches for evaluating transmission warming technology: experimental dynamometer testing and development of a simplified transmission efficiency model to quantify effects under varied real world ambient and driving conditions. Two vehicles were used for this investigation: a 2013

Ford Taurus and a highly instrumented 2011 Ford Fusion (Taurus and Fusion). The Taurus included a production transmission warming system and was tested over hot and cold ambient temperatures with the transmission warming system enabled and disabled. A robot driver was used to minimize driver variability and increase repeatability. Additionally the instrumented Fusion was tested cold and with the transmission pre-heated prior to completing the test cycles. These data were used to develop a simplified thermally responsive transmission model to estimate effects of transmission warming in real world conditions.
\end{abstract}

For the Taurus, the fuel consumption variability within one standard deviation was shown to be under $0.5 \%$ for eight repeat Urban Dynamometer Driving Cycles (UDDS). These results were valid with the transmission warming system active or passive. Using the transmission warming system under $22^{\circ} \mathrm{C}$ ambient temperature, fuel consumption reduction was shown to be $1.4 \%$. For the Fusion, pre-warming the transmission reduced fuel consumption $2.5 \%$ for an urban drive cycle at $-7^{\circ} \mathrm{C}$ ambient temperature, with $1.5 \%$ of the $2.5 \%$ gain associated with the transmission, while consumption for the US06 test was shown to be reduced by $7 \%$ with $5.5 \%$ of the $7 \%$ gain associated with the transmission. It was found that engine warming due to conduction between the pre-heated transmission and the engine resulted in the remainder of the benefit. For $+22^{\circ} \mathrm{C}$ ambient tests, the pre-heated transmission was shown to reduce fuel consumption approximately $1 \%$ on an urban cycle, while no benefit was seen for the US06 cycle. The simplified modeling results showed gains in efficiency ranging from $0-1.5 \%$ depending on the ambient temperature and drive cycle.

\section{Introduction}

In 2012, new light-duty fuel consumption standards were set for the North American market. The U.S. Environmental Protection Agency (EPA), National Highway Traffic Safety Administration (NHTSA), California Air Resources Board, OEMs, non-government entities, and other stakeholders collaborated to define the 2012-2025 national fuel consumption and greenhouse gas standards. The program called for a $4 \%-5 \%$ annual improvement in fuel consumption with the final car and light-duty truck standard set to 54.5 miles per gallon [1]. Vehicle manufacturer fleet fuel consumption certification for this Corporate Average Fuel consumption regulation is determined via a combination of on- and off-cycle methods. On-cycle certification is evaluated from weighted measured testing results of EPA's test cycles $[\underline{2}, \underline{3}]$. On-cycle certification can be supplemented with off-cycle credits representing estimated real-world vehicle efficiency not captured by on-cycle testing. The EPA and NHTSA recognize three pathways by which technologies can qualify for off-cycle credit:

1. On-Table - An OEM gets a predefined credit value for technologies that are included in the credit table.

2. 5-Cycle-An OEM uses a predefined 5-cycle test methodology to determine credit value.

3. Alternative Method - An OEM may develop and justify a test methodology and credit value using real-world data.

As new technologies are developed there is a strong interest in assessing fuel-savings potential that are difficult to ascertain with standard laboratory certification cycles (e.g. thermally-sensitive components, driver/cabin comfort, connected/automated driving, etc.). With this understanding, DOE and regulatory bodies want to maximize real-world fuel savings. Additionally, manufacturers desire to obtain appropriate credit for actual fuel savings achieved. As such, the relatively new alternative method listed above serves as a platform for the manufacturers to demonstrate actual fuel savings technology that may not be represented in the other two methods. 
In one work [4] , the Joint Technical Support Document cites a simulation study that suggested a fully warm vehicle to reduce greenhouse gas emissions (GHG) by $7 \%$ at $20^{\circ} \mathrm{F}$ ambient conditions. Currently, the EPA/NHTSA assume transmissions to make up $1 / 3$ of the $7 \%$ total benefit $(2.3 \%)$. This benefit is assumed to decay linearly down to zero at $72^{\circ} \mathrm{F}$ where benefit can be measured on-cycle. Data was used to calculate the total vehicle miles travel (VMT) weighted against the calculated average ambient temperature of $58^{\circ}$. In Figure $\underline{1}$, this corresponds to a $0.58 \%$ benefit in a linear model. The VMT data may be seen in Figure 2. Combining the sales-weighted baseline efficiency values, results translate percent into absolute benefit of 1.5 $\mathrm{gCO}_{2} / \mathrm{mi}$ (cars) and $3.2 \mathrm{gCO}_{2} / \mathrm{mi}$ (light-duty trucks).

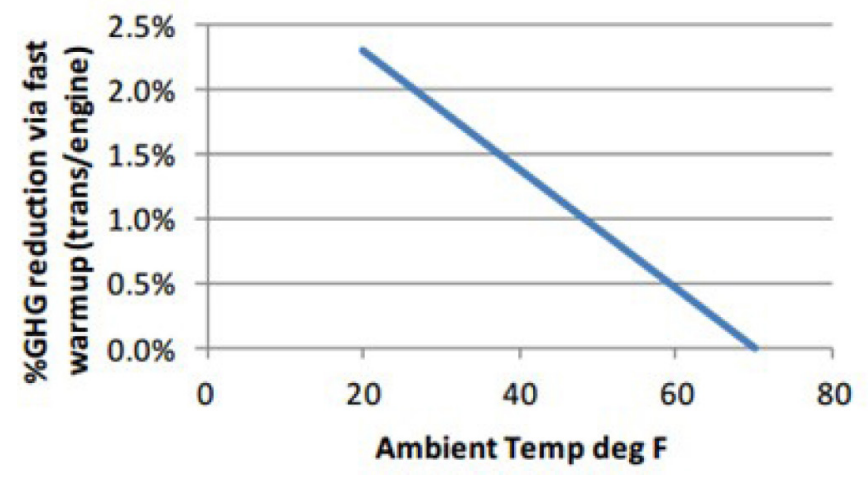

Figure 1. Greenhouse gas reduction via fast warmup for both engine and transmission, MOVES data

\section{\% VMT (from MOVES)}



Figure 2. Weighted percent vehicle miles traveled (VMT) as a function of ambient temperature, U.S. market MOVES data.

In previous works that focused on real-world effects on powertrain efficiency $[\underline{5}, 7]$ simplified thermal models of a conventional vehicle were developed from experimental testing data to predict real-world effects on vehicle efficiency. From this work it was shown that regional temperature variations play a significant role in vehicle engine efficiency. Additional work was done to better understand thermal losses associated with wheel assemblies as a function of thermal state $[\underline{8}]$.

The approach outlined in this paper involves experimental vehicle chassis dynamometer testing conducted over varied ambient conditions and drive cycles. For the Taurus, active transmission warm-up tests were conducted with the system enabled and disabled. Additional tests were conducted on the Fusion by partially prewarming the transmission fluid, completing the tests, and comparing the results to a non-preheated transmission. The data from this effort were then used to develop a simplified thermally sensitive transmission efficiency model that could be used to investigate transmission warming technology impacts under real world conditions. The goal of this approach is to ultimately integrate all results into an experimentally data derived, simplified model $[\underline{5}, \underline{7}, \underline{8}]$, that allows for analysis of fuel efficiency gains of technologies applied to real world conditions.

\section{Approach and Test Setup}

\section{Experimental Testing}

Tests were conducted at Argonne National Laboratory's Advanced Powertrain Research Facility (APRF) four-wheel-drive dynamometer test cell [9]. The four wheel-drive (4WD) dynamometer test facility is designed to handle light- to medium-duty sized (maximum 6,350 kg) vehicles capable of producing up to $373 \mathrm{~kW}$ of wheel power. The test cell is EPA 5-cycle-capable with an ambient temperature capability from $-20^{\circ} \mathrm{C}$ to $+36^{\circ} \mathrm{C}$. A vehicle speed-matching simulation fan fulfills the test regulations for the SC03 air-conditioning test. The cell also contains solar lamps simulating real-world solar loading, with a typical target solar loading of $850 \mathrm{~W} / \mathrm{m}^{2}$ at the windshield base or rear window. The test cell contains emission benches measuring the criteria emissions of total hydrocarbons, oxides of nitrogen, carbon monoxide, and soot, as well as carbon dioxide for cycle fuel consumption. A turbine wheel fuel cart is used to accurately measure fuel. Power meters are available to characterize vehicle electrification loads, fast FID and NOx benches are available, as well as particulate measurement capabilities. A modular data acquisition combines CAN, analog, digital, and facility data into a single output file.

Two vehicles were used for testing: a 2013 Ford Taurus and a 2011 Ford Fusion. The Taurus contained transmission warming devices, whereas the Fusion did not. However, the Fusion has been highly instrumented by APRF staff to characterize accurate transmission efficiencies as a function of thermal state to develop and experimental data driven model. Table 1 summarizes the test vehicle specifications.

Table 1. Test vehicle specifications.

\section{Ford Fusion 2013 Ford Taurus}

\begin{tabular}{lll}
\hline Drive & Front-wheel drive & Front-wheel drive \\
\hline Engine & $\begin{array}{l}\text { 2.5L DOHC port- } \\
\text { fuel injected } \\
\text { aluminum engine }\end{array}$ & $\begin{array}{l}\text { 2.0L I4, turbocharged, } \\
\text { direct injection }\end{array}$ \\
\hline Transmission & $\begin{array}{l}\text { 6-speed, hydraulic } \\
\text { torque converter, } \\
\text { automatic } \\
\text { transmission }\end{array}$ & $\begin{array}{l}\text { 6-speed, hydraulic } \\
\text { torque converter, } \\
\text { automatic } \\
\text { transmission }\end{array}$ \\
\hline $\begin{array}{l}\text { EPA } \\
\text { city/highway }\end{array}$ & $23 / 33$ & $22 / 32$ \\
\hline $\begin{array}{l}\text { Wheelbase } \\
\text { [cm] }\end{array}$ & 273 & 287 \\
\hline $\begin{array}{l}\text { Vehicle Test } \\
\text { Weight [kg] }\end{array}$ & 1,490 & 1,830 \\
\hline
\end{tabular}

EPA urban and highway driving schedules tests were conducted at three ambient temperatures: $-7^{\circ} \mathrm{C},+22^{\circ} \mathrm{C}$, and $+35^{\circ} \mathrm{C}$. Vehicles were soaked at these ambient temperatures overnight prior to testing. For each testing sequence, vehicles ran multiple back-to-back urban 
cycles until relative thermal stability was achieved. This stability was achieved for a different number of cycles depending on the vehicle, ambient temperature, and drive cycle.

\section{Ford Taurus Test Setup}

Fuel consumption was recorded via carbon count emissions bench measurements in addition to a turbine wheel volumetric flow fuel meter. Thermocouples were used to measure engine transmission drain plug, transmission cooling line (to transmission warmer), and engine oil dipstick temperatures. CAN signals were used to record other pertinent parameters (engine coolant temperature, transmission temperature, transmission warmer on/off, etc). Additionally, solenoid voltage to the transmission warmer was recorded with a Hioki power meter. To de-activate the transmission warming system the solenoid was powered directing flow through the bypass valve. To reduce driver variability a robot driver was used to drive the vehicle. This system has been shown to reduce velocity variations resulting highly repeatable fuel consumption measurements. The vehicle test setup may be seen in Figure 3. A diagram of the transmission warming system may be seen in Figure 4.

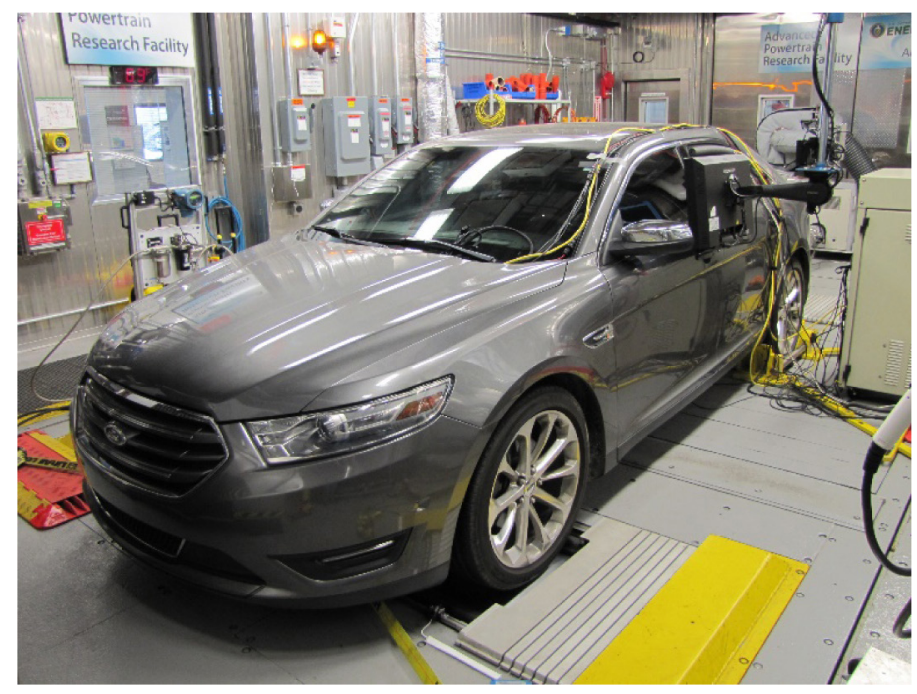

Figure 3. 2013 Ford Taurus on Argonne's APRF dynamometer for testing.


Figure 4. 2013 Ford Taurus transmission warming system diagram.

\section{Ford Fusion Test Setup}

To characterize and develop a simplified transmission model, extensive instrumentation was utilized for the Ford Fusion. Strainbased torque measurement systems were installed on the front half-shafts. This enabled measurement of the transmission output torque. The half-shaft torque measurement transmits torque signals from rotating shafts to a stationary telemetry receiver. Strain gages were bonded to the half-shafts to measure rotational strain, this signal transmitted to a receiver and matched to a calibration curve. Power to the pickup was supplied to the telemetry slip ring collar inductively through a stationary loop adapter. Full-scale torque measurements were set at 3,400 Nm with a maximum static measured error of $0.2 \%$. Transmission input power was measured via an engine torque system. Similar to the half-shafts, the engine flexplate was instrumented with strain gages also measuring rotational strain. These signals were also transmitted to a receiver mounted on the transmission housing and matched to a calibration curve. Full-scale torque measurements were set at $500 \mathrm{Nm}$ with a maximum static measured error of $0.2 \%$. The systems may be seen in Figures 5 and $\underline{6}$.

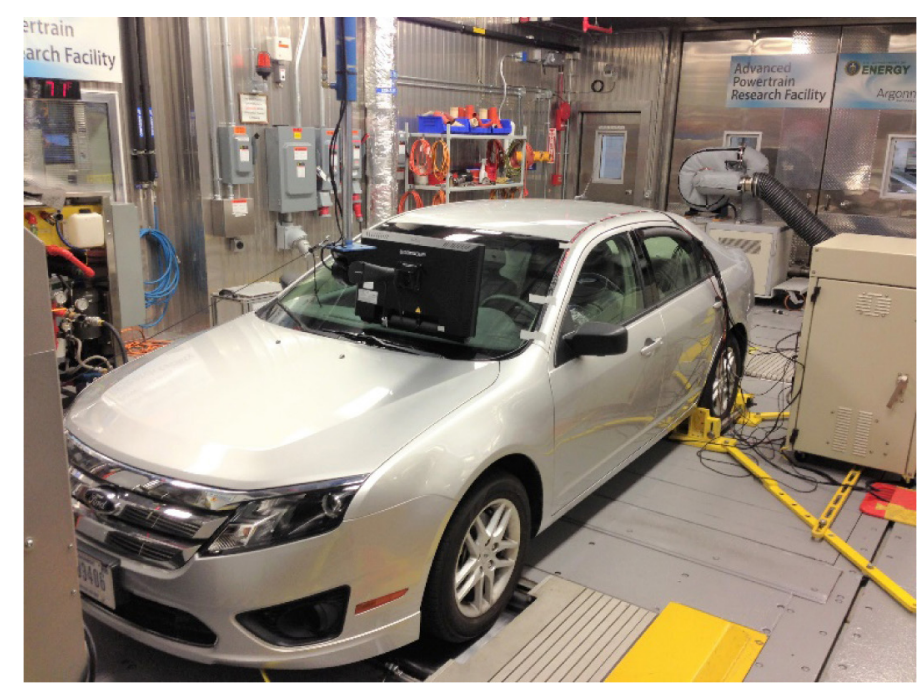

Figure 5. 2011 Ford Fusion test vehicle on Argonne's APRF dynamometer for testing.



Half-shaft torque measurement system

Figure 6. 2011 Ford Fusions half-shaft and engine torque sensing system. 


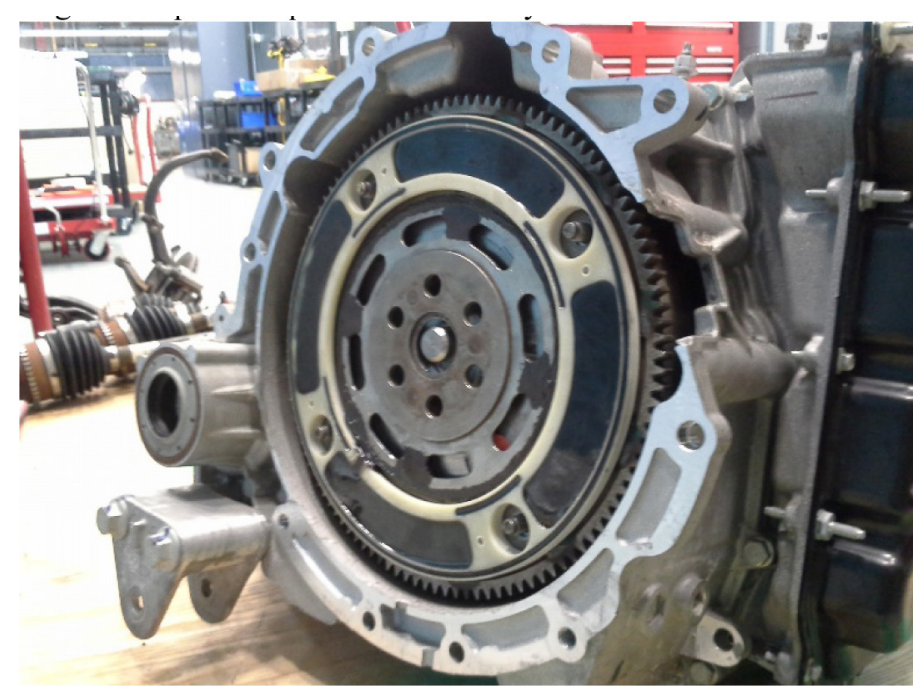

Engine flex plate torque measurement system

Figure 6 (cont). 2011 Ford Fusions half-shaft and engine torque sensing system.

To calculate total half-shaft power, rotational speed measurements of the wheels were recorded directly. The power at the contact patch of the wheel and the dynamometer roll was recorded via the dynamometer load cell. The wheel hub dynamometer power was recorded by the wheel hub motor load cells. Figure 7 depicts the pertinent energy nodes collected for the Fusion.

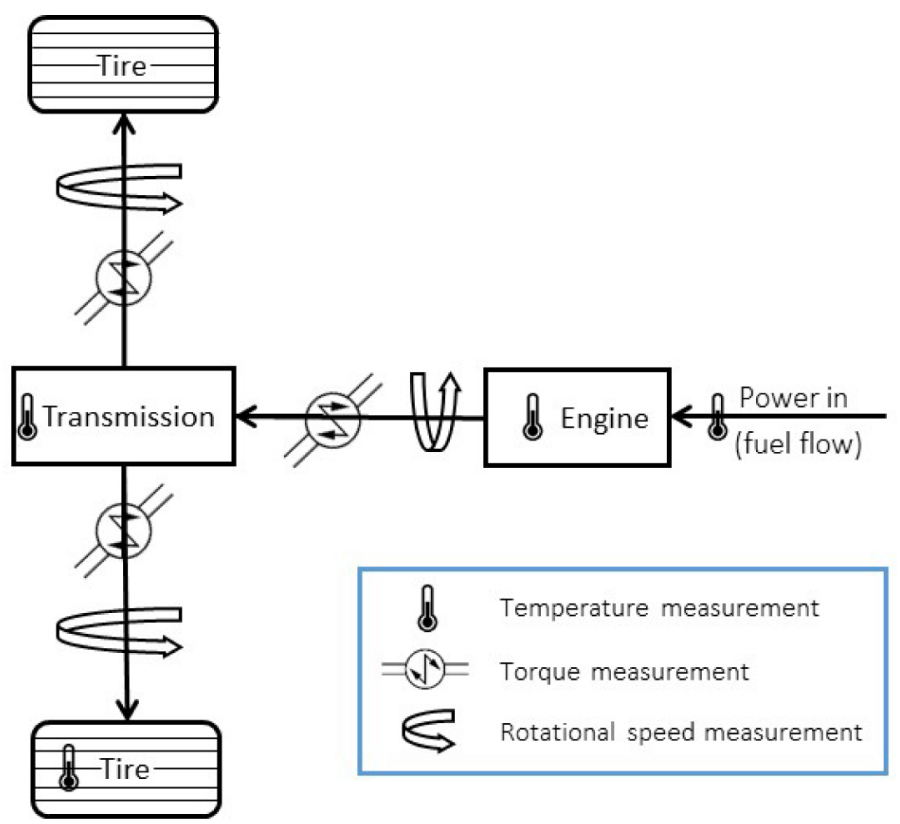

Figure 7. Ford Fusion Test vehicle instrumentation layout.

To develop the Fusion simplified thermally responsive transmission model, tests were conducted in which the transmission was both cold soaked to ambient and partially pre-heated prior to the start of the test. For warming, two warming pads totaling 375 watts were fixed to the surface of the transmission and allowed to heat the transmission overnight. This resulted in initial transmission temperatures approximately $30^{\circ} \mathrm{C}$ warmer at the start of the test for the pre-heated case.

\section{Ford Fusion Thermally Sensitive Simplified Transmission Model Development}

Data from the Fusion was used to develop a lumped capacitance, thermally sensitive, predictive transmission efficiency model. This model was input into an experimental data derived simplified, backwards facing, vehicle model developed in earlier work [ $[\underline{5}, \underline{7}]$. Experimental dynamometer test data were used to develop transmission efficiency as a function of the transmission thermal state and operating condition. Operating conditions included the input power (from the engine), the current transmission thermal state (transmission oil temperature), torque convertor efficiency (lock-up versus non-lock up conditions), and transaxle/gearbox efficiency. Inputs to determine the torque convertor model coefficients were gear number, time in gear, and transmission oil temperature. The gearbox control model coefficients were determined using vehicle speed, required transmission output power, and oil temperature. The transaxle/gearbox efficiency coefficients were determined using gear number, transmission output power, and oil temperature. Finally, oil temperature was determined using ambient temperature, engine oil temperature, transmission power loss, and vehicle speed. The lumped capacitance coefficients were calculated by minimizing the aggregate sum of least squares error in comparison to the experimental dynamometer measured efficiencies. This simplified thermal model was linked to variable ambient temperature data and a national database of vehicle usage [10]. A summary of the mechanical model power flow may be seen in Figure 8. Table 2 and Table 3 list the individual sub-component vehicle efficiency models and the variables used as inputs. This simplified model was used to investigate potential real world benefit of active transmission warming.

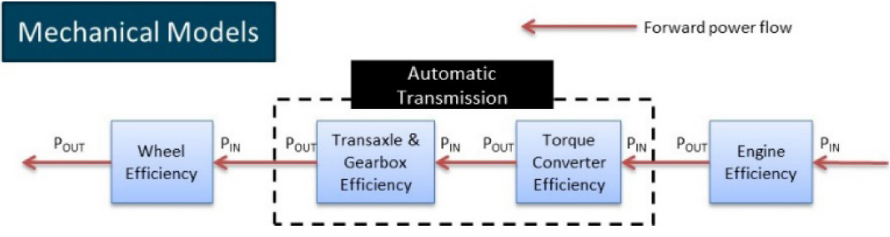

Figure 8. Simplified mechanical model power flow layout.

Table 2. Thermally sensitive transmission efficiency sub-model inputs

\begin{tabular}{|l|l|}
\hline Sub-component model & Inputs \\
\hline Torque converter control & $\begin{array}{l}\text { Gear number } \\
\text { Time in gear } \\
\text { Transmission oil temperature }\end{array}$ \\
\hline $\begin{array}{l}\text { Gearbox control } \\
\text { (shift schedule) }\end{array}$ & $\begin{array}{l}\text { Vehicle speed } \\
\text { Transmission output power } \\
\text { Transmission oil temperature }\end{array}$ \\
\hline Transaxle/gearbox efficiency & $\begin{array}{l}\text { Gear number } \\
\text { Transmission output power } \\
\text { Transmission oil temperature }\end{array}$ \\
\hline Transmission oil temperature & \begin{tabular}{l} 
Ambient temperature \\
Engine oil temperature \\
Transmission power loss \\
\hline
\end{tabular} \\
\hline
\end{tabular}


Table 3. Thermally sensitive simplified engine efficiency sub-model inputs

\section{Sub-component model}

Inputs

\begin{tabular}{|l|l|}
\hline Engine efficiency & $\begin{array}{l}\text { Engine output power } \\
\text { Engine oil temperature } \\
\text { Exhaust catalyst temperature }\end{array}$ \\
\hline Wheel efficiency & $\begin{array}{l}\text { Wheel output power } \\
\text { Wheel temperature }\end{array}$ \\
\hline
\end{tabular}

\section{Results}

\section{Ford Taurus}

Because measured efficiency gains from transmission warming could be small, analysis on fuel consumption testing repeatability was first completed. To determine fuel consumption testing repeatability eight repeat UDDS tests at $+22^{\circ} \mathrm{C}$ ambient temperature were completed and one standard deviation of fuel consumption calculated. Each test consisted of driving four UDDS cycles with 10 minute soaks in between each cycle. Fuel consumption was then averaged for cycles in which the vehicle powertrain engine pan oil temperature $>+90^{\circ} \mathrm{C}$ and engine coolant temperature $>+100^{\circ} \mathrm{C}$. This test sequence was completed with the transmission warming system enabled and disabled. The drive cycle profile is shown in Figure 9 with fuel consumption results shown in Figure 10.

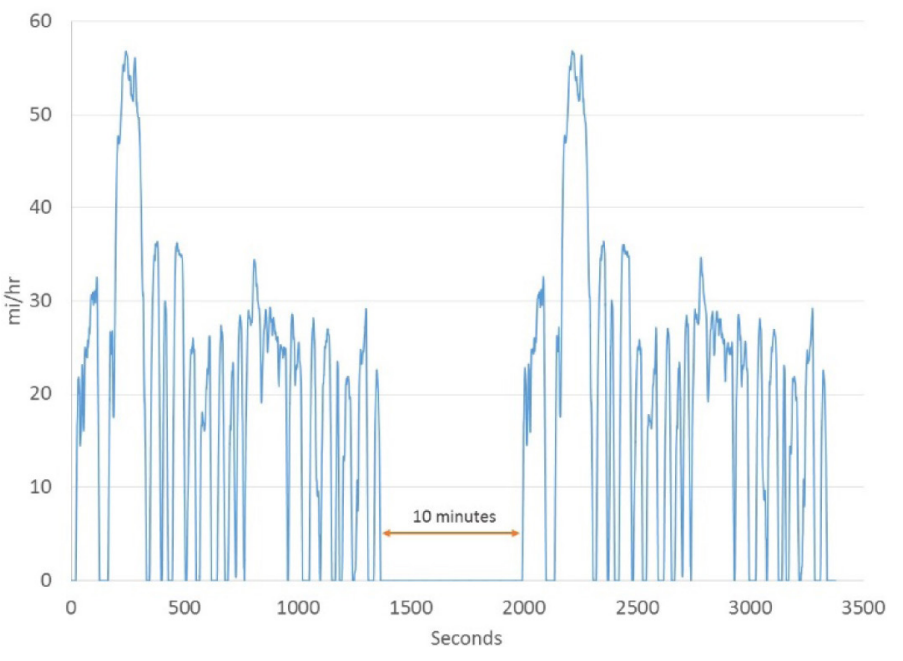

Figure 9. Taurus Urban FTP repeat UDDS cycles used for determining measured fuel consumption variability, repeat tests with 10 minute soaks in between cycles.

First, the results shown in Figure 10 predictably do not demonstrate any advantage with the transmission warmer active. This was anticipated as the data used to determine repeatability were only from cycles in which the vehicle powertrain was already warm. With regards to fuel consumption repeatability, fuel consumption for the eight tests with a one-standard deviation confidence interval was shown to be within $0.2 \%$ for the active transmission warmup enabled and $0.4 \%$ for the transmission warmup disabled from the average of eight runs each. From these results it is shown that cycle tested fuel consumption repeatability for the Taurus was conservatively within $0.5 \%$. To estimate the fuel consumption benefit of active transmission warming, three cold start UDDS tests were completed and fuel use averaged (six tests total). Tests were completed at $+22^{\circ} \mathrm{C}$ ambient temperatures with the vehicle soaked overnight prior to testing. A robot driver was used to minimize driving variability. Figures 11 through 13 display lubricant and coolant temperatures for six tests with the transmission system both on and off, while Figure 14 shows the fueling rate for the first 505 seconds of the UDDS cycle for the tests. This empirically shows extremely repeatable vehicle temperatures and fuel consumption from test to test.

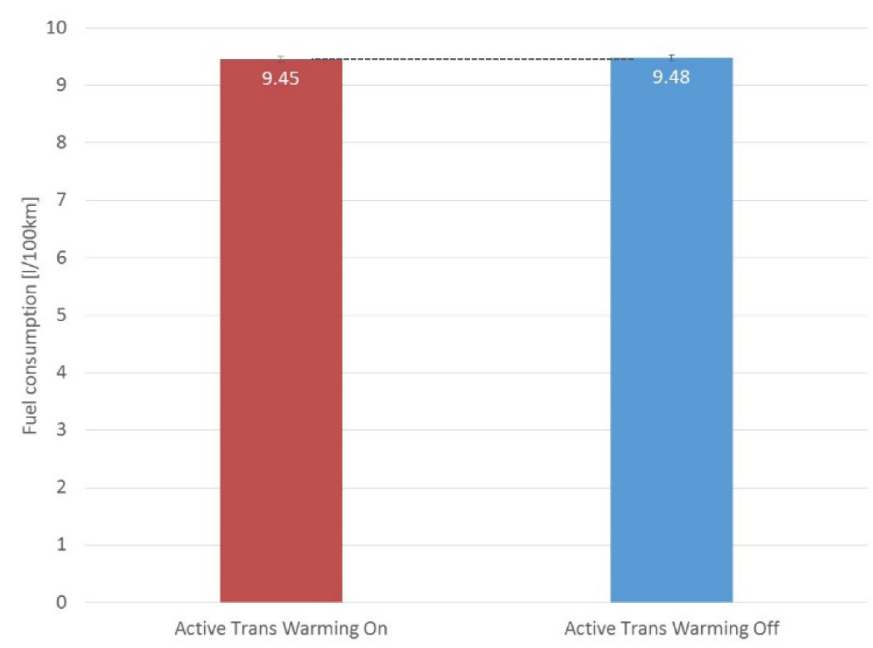

Figure 10 . Taurus $22^{\circ} \mathrm{C}$ ambient UDDS fuel consumption variability comparison with transmission heater on and off, vehicle warm (no cold starts), $0.5 \%$ error bars shown for 1 -standard deviation confidence interval for eight drive cycles.



Figure 11. Taurus transmission oil temperature over four UDDS cycles, $22^{\circ} \mathrm{C}$ ambient temperature, warming system on and off. 


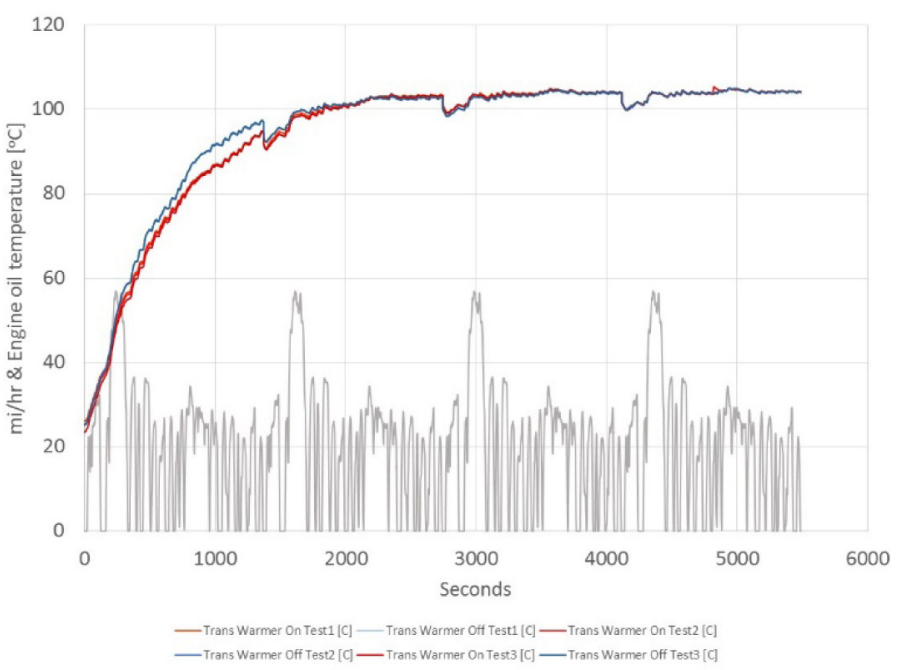

Figure 12. Taurus engine oil temperature over four UDDS cycles, $22^{\circ} \mathrm{C}$ ambient temperature, warming system on and off.

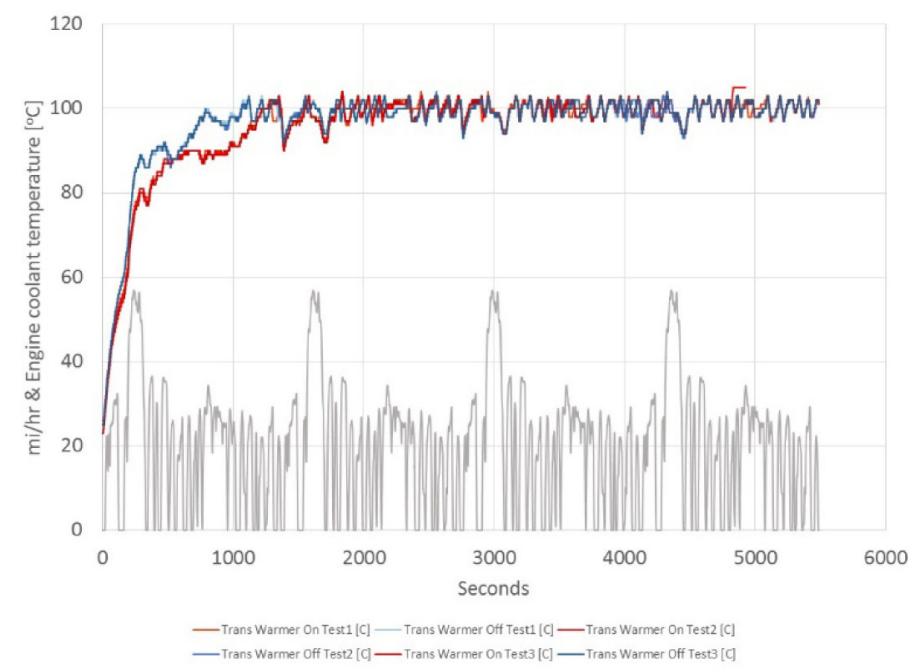

Figure 13. Taurus engine coolant temperature over four UDDS cycles, $22^{\circ} \mathrm{C}$ ambient temperature, warming system on and off.

From these Figures it may be seen that the powertrain lubricant and coolant temperatures between tests exhibit variations within a single degree centigrade. By the beginning of the third UDDS cycle the transmission fluid temperature has converged with the transmission heater active and disabled. After the engine coolant temperature is greater than $+60^{\circ} \mathrm{C}$ the transmission warming valve opens allowing the coolant to warm the transmission resulting in temperatures $20^{\circ} \mathrm{C}$ warmer than the case in which the system was off. Contrarily the coolant and engine temperature drop as energy is transferred from the coolant to the transmission. However, these drops are small relative to the increase in transmission fluid temperature. In Figure 14 the fuel flow for the first 505 seconds of the UDDS cycle (bag 1) are shown for the six test cases in which the transmission warmer enabled and disabled. These results demonstrate that repeatability is excellent, with fueling slightly higher for accelerations for case in which the transmission warmer is disabled.

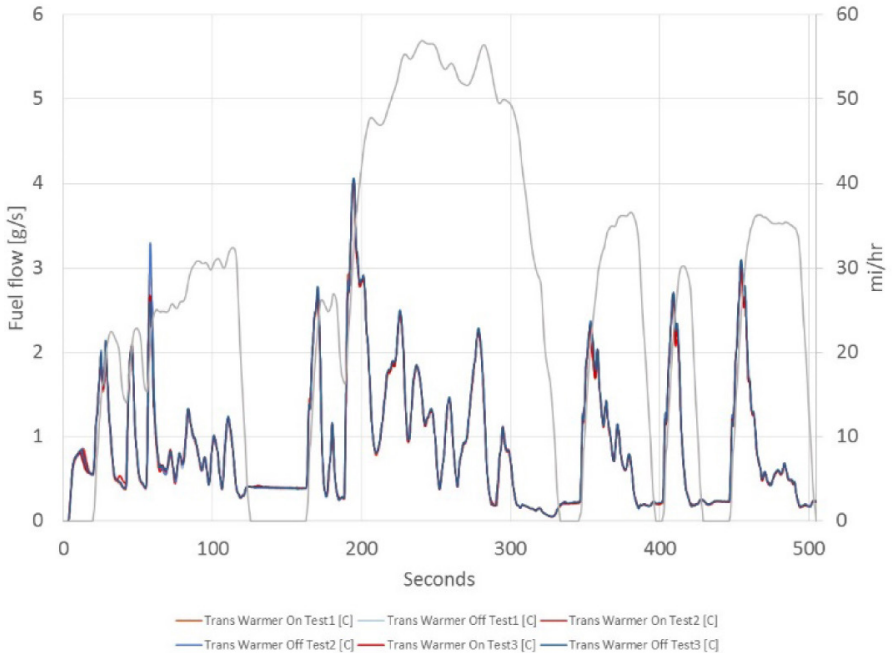

Figure 14. Taurus engine fuel flow over four UDDS cycles, $22^{\circ} \mathrm{C}$ ambient temperature, warming system on and off.

Demonstrating the effect that transmission warming has on fuel consumption, four back-to-back UDDS cycles completed at $22^{\circ} \mathrm{C}$ ambient temperature are contrasted and shown in Figure 15. Fuel consumption is lower for the case in which transmission warmup occurred in the first two cycles. Figure 11 supports this finding as the transmission lubricant temperature is significantly higher in temperature for large portions of the cycles before coming to a similar final operational temperature without warming. By the time the third cycle is reached temperature has stabilized and the fuel consumption nearly identical. In Figure 16 averaged fuel consumption over three tests for the cold start UDDS cycle was compared with the transmission warming system enabled and disabled. Results show a $1.4 \%$ increase in fuel consumption with the system disabled (which was above the $0.5 \%$ fuel consumption testing repeatability determined earlier).

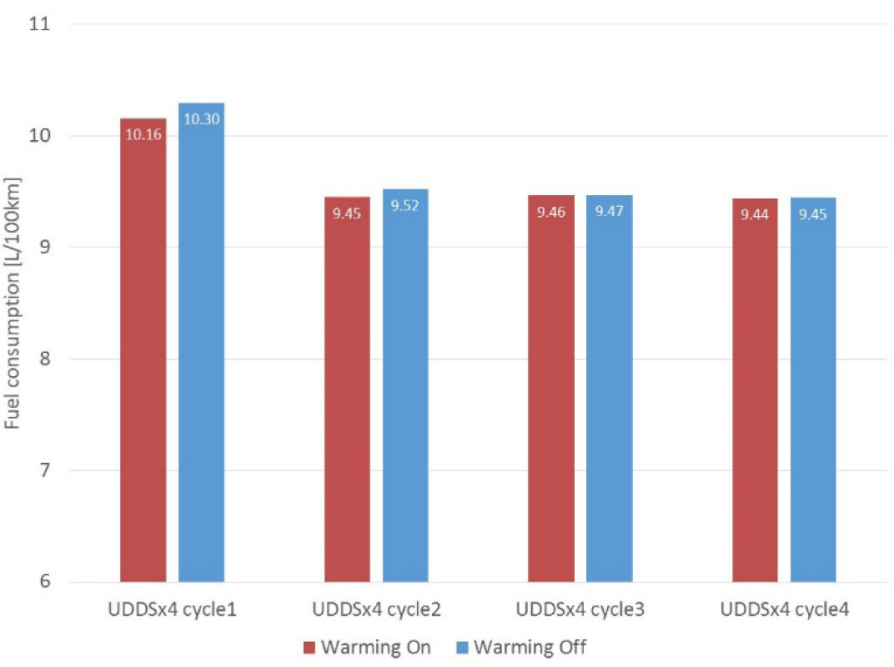

Figure 15. Taurus UDDS cycle fuel consumption with four repeat cycles, $22^{\circ} \mathrm{C}$ ambient temperature with transmission warming system on and off. Each value is the average of three cycles. 


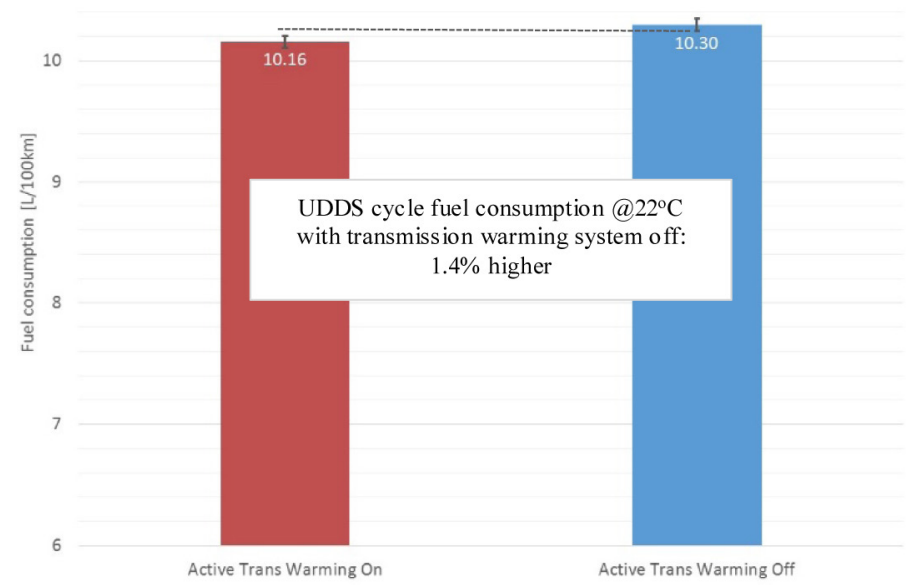

Figure 16. Taurus UDDS cycle \#1 fuel economy, $22^{\circ} \mathrm{C}$ ambient temperature, warming system on and off.

Finally, four back-to-back UDDS cycles were completed at $-7^{\circ} \mathrm{C}$ ambient temperatures to determine the effect active transmission warming had under colder conditions. Identical to the $+22^{\circ} \mathrm{C}$ ambient case tests were conducted with the transmission warming system active and deactivated. Results are shown in Figure 17.

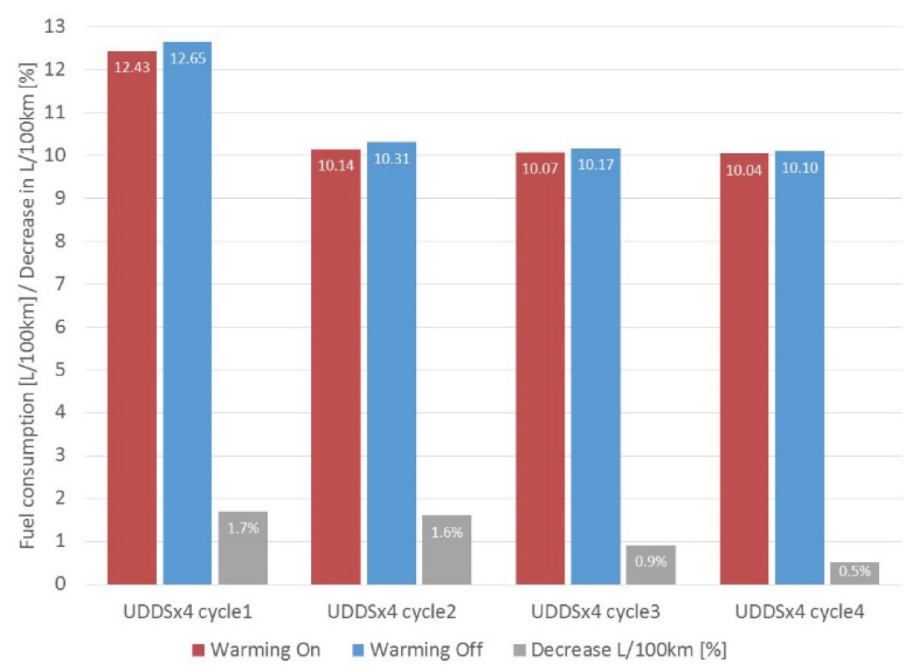

Figure 17. Taurus UDDS cycle fuel consumption with four repeat cycles, $-7^{\circ} \mathrm{C}$ ambient temperature with transmission warming system on and off. Included is the $\%$ reduction in fuel consumption utilizing active transmission warming.

From this it may be seen that at colder temperatures the transmission warming system exhibits greater benefit through all the cycles. For the first cycle, fuel consumption was reduced $1.7 \%$, and by the fourth UDDS a $0.5 \%$ decrease was still seen (though approaching the measurement confidence interval). The difference in transmission temperatures between these cases are shown in Figure 18. It is worth noting in the case of the active transmission warmer deactivated that transmission temperature rises above the case with the system active. This would suggest potentially better fuel consumption in the case without. However, lubricity gains in that temperature range are much less than at cold temperatures, additionally, the benefit of $0.5 \%$ is approaching the testing repeatability confidence interval.

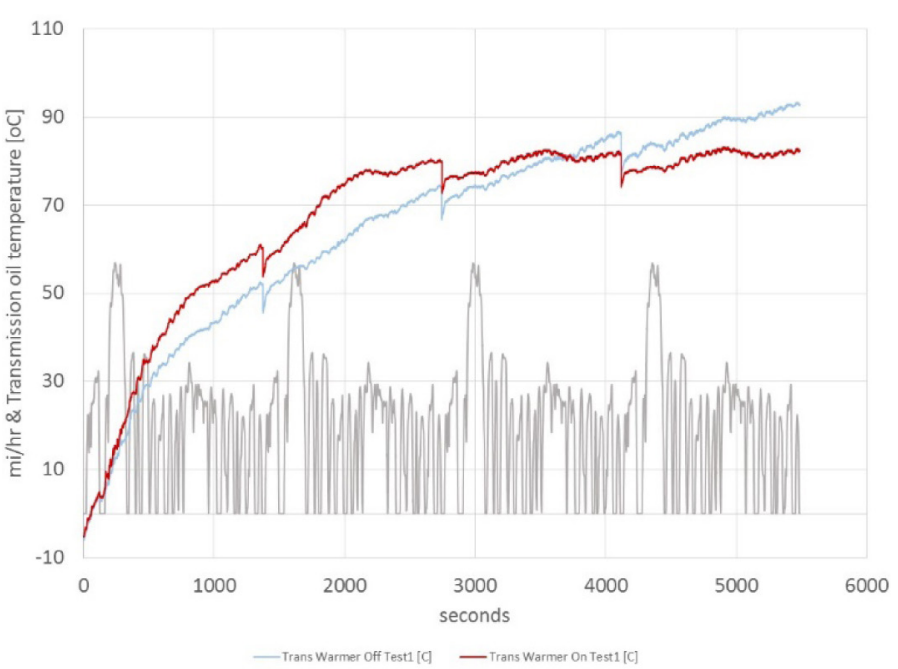

Figure 18. Taurus Transmission oil temperature over four UDDS cycles, $-7^{\circ} \mathrm{C}$ ambient temperature, warming system on and off.

\section{Ford Fusion Thermal Mule}

Tests were completed utilizing two heaters with a total of $375 \mathrm{~W}$ fixed to the outside of the transmission in order to warm the fluid prior to driving the cycle. Although this is not realistic in an active transmission warming scenario, these tests generated the data necessary to develop a simplified thermally sensitive transmission model.

Figure 19 and Figure 20 show the difference in transmission and engine oil temperature warming profiles over the four cycles. Although one finds a significant increase in initial transmission starting temperature for the heated case, transmission heaters also warmed the engine for the first cycle (via conduction) as shown in Figure 20. Note that the step jump in oil temperature occurring between 700-800 seconds as shown in Figure 20 is due to the thermostat opening allowing hot coolant to flow through the block thereby increasing lubricant temperature. Fuel consumption for each cycle and the relative difference between pre-warming on and off is shown in Figure 21 and summarized in Figure 22.

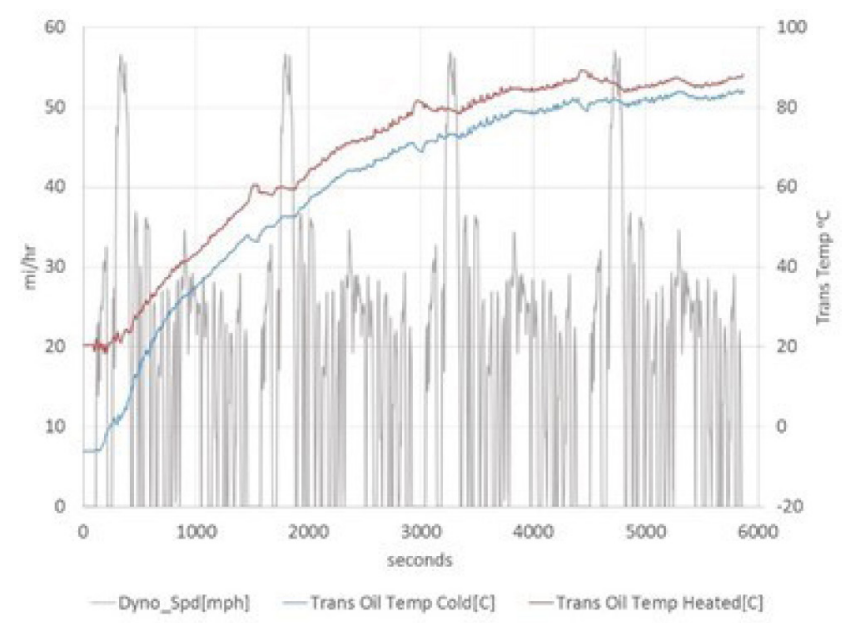

Figure 19. Transmission oil temperature profile, four back-to-back UDDS cycles with transmission pre-warming on and off, $-7^{\circ} \mathrm{C}$ ambient temperature. 


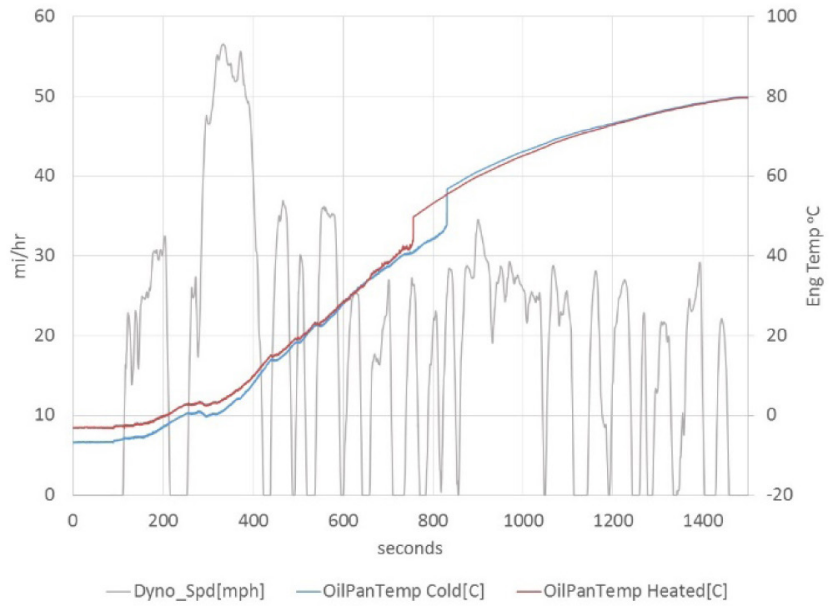

Figure 20. Engine oil temperature profile, first of four back-to-back UDDS cycles with transmission pre-warming on and off, $-7^{\circ} \mathrm{C}$ ambient temperature.

From the UDDS cycle results shown in Figure 22 an approximate $2.5 \%$ reduction in fuel consumption for the first UDDS cycle with the transmission pre-heated is shown. Pre-warming the transmission results in approximately $25^{\circ} \mathrm{C}$ higher initial fluid temperature, yet by the second cycle the temperature delta has significantly decreased such that benefits could not be measured with statistical confidence. Note that Fusion testing did not utilize the robot driver so results were not as repeatable as the Taurus testing.

12

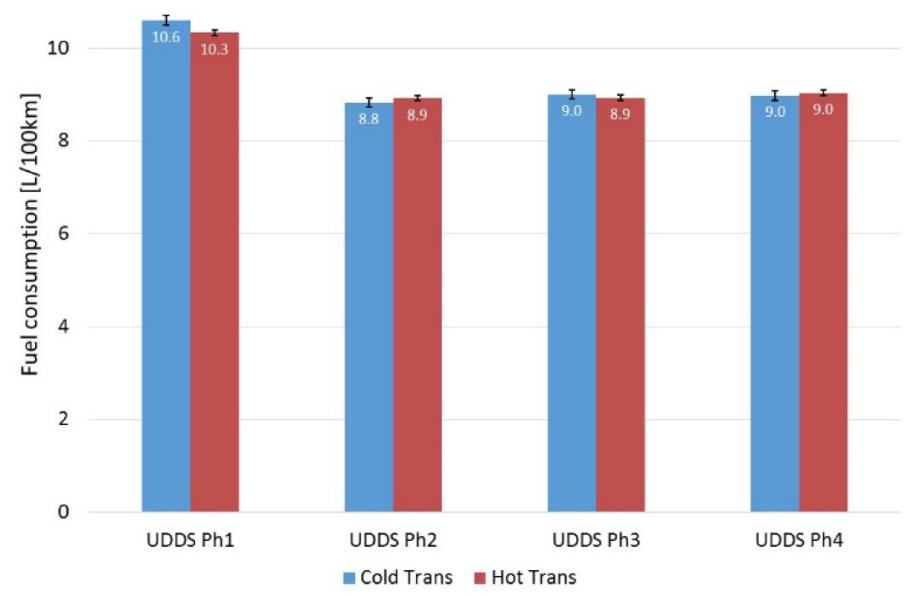

Figure 21. Fuel consumption for back-to-back UDDS cycles with transmission pre-warming on and off, $-7^{\circ} \mathrm{C}$ ambient temperature.

In light of the engine being warmed due to heat transfer from the external transmission heater (igure 20), analysis was done to separate out increased engine lubricant temperature from transmission effects. Efficiency across the engine and transmission were compared for positive tractive force only portions of the cycle (accelerations) with the heaters on and off. Results are presented in Figure 23. It is shown that for positive tractive force portions of the cycle the transmission efficiency improved 5.5\% with pre-heated transmission lubricant whereas the engine efficiency declined 2.1\% over the first UDDS cycle at $-7^{\circ} \mathrm{C}$. Although counter intuitive, when the vehicle system is cold the engine requires higher power levels to overcome losses which results in higher loaded conditions. Although the total fuel consumed increases, the higher engine loads effectively reduce pumping losses so that efficiency may be slightly higher. It is important to note that this analysis only applies to accelerations; cold-start, idle, and deceleration effects are not considered. If the total cycle is included in the analysis the engine may not show an aggregate increase in efficiency.

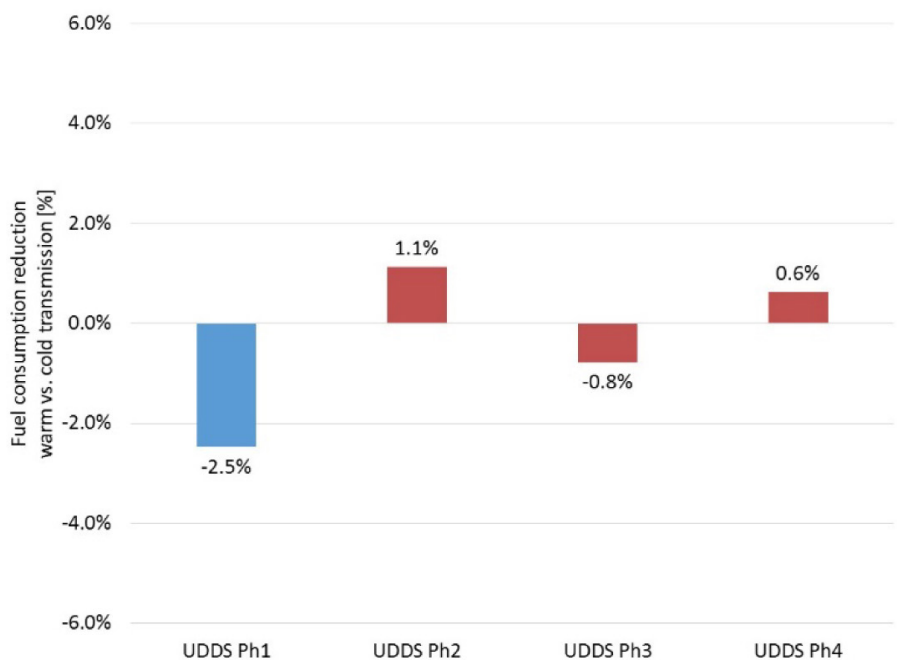

Figure 22. Fuel consumption reduction for back-to-back UDDS cycles with transmission pre-warming on, $-7^{\circ} \mathrm{C}$ ambient temperature.

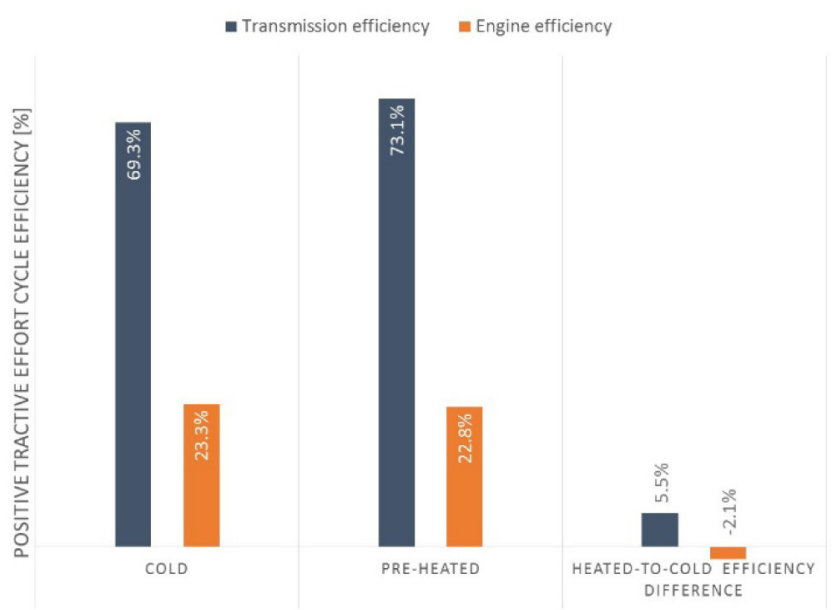

Figure 23. Positive tractive force engine and transmission efficiency, heated vs. cold, UDDS cycles $-7^{\circ} \mathrm{C}$ ambient temperature.

Similarly to the UDDS cycle analysis, transmission and engine temperature profiles were compared over the US06 cycle tested at $-7^{\circ} \mathrm{C}$ and are presented in Figure 24 and Figure 25. In this case, the transmission began with approximately $25^{\circ} \mathrm{C}$ higher fluid temperature in the pre heated case and the engine oil was slightly warmer as well. 


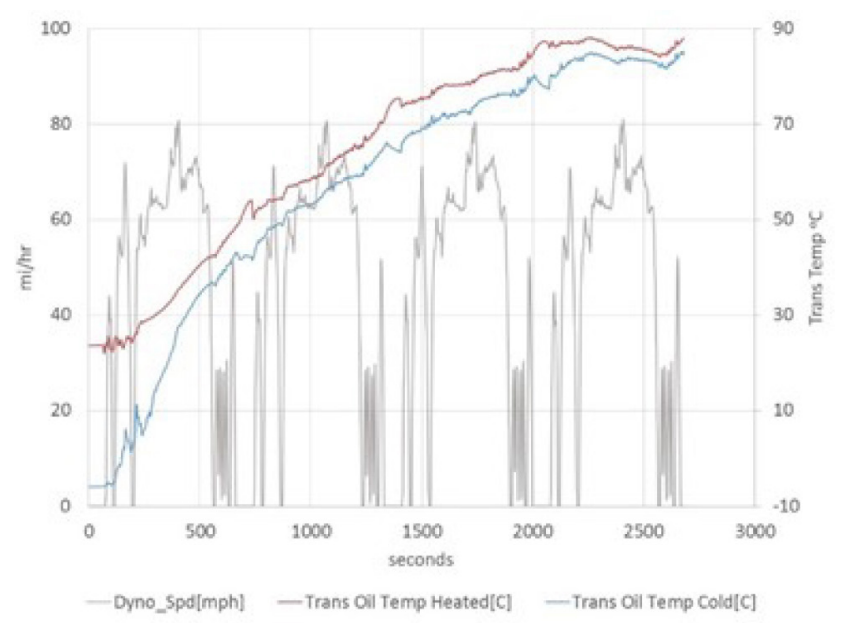

Figure 24. Transmission oil temperature profile, four back-to-back US06S cycles with transmission pre-warming on and off, $-7^{\circ} \mathrm{C}$ ambient temperature

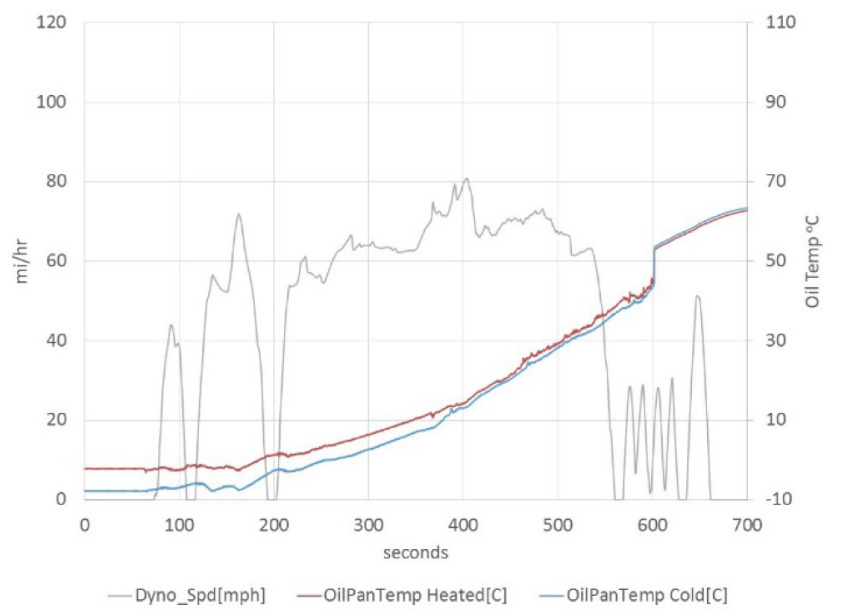

Figure 25. Engine oil temperature profile, first of four back-to-back UDDS cycles with transmission pre-warming on and off, $-7^{\circ} \mathrm{C}$ ambient temperature.

Presenting fuel consumption results for the US06 cycle in Figure 26, a significant statistical measurable improvement between the first cycle and the ones following is shown. Figure 27 summarizes an approximate $7 \%$ improvement in fuel consumption for the pre-heated case versus the cold case for the first cycle. After the first cycle no statistical significant difference can be measured.

Following similar analysis as the UDDS case study, positive tractive force efficiencies for the engine and transmission for the first cycle are provided in Figure 28. Transmission efficiency increased $1.5 \%$ for the accelerations portions of the cycle in the pre-heated case and that the engine increased $4.6 \%$. Since the US06 cycle has higher loading than the UDDS cycle, partial throttle pumping losses are reduced so that the efficiency gain presented in Figure 23 are not present. The higher loading also results in higher losses earlier in the cycle such that the warmer engine temperature has a larger positive impact on fuel consumption. Transmission losses in this case were shown to play a less significant role yet resulted in a statistically measureable improvement of $1.5 \%$.

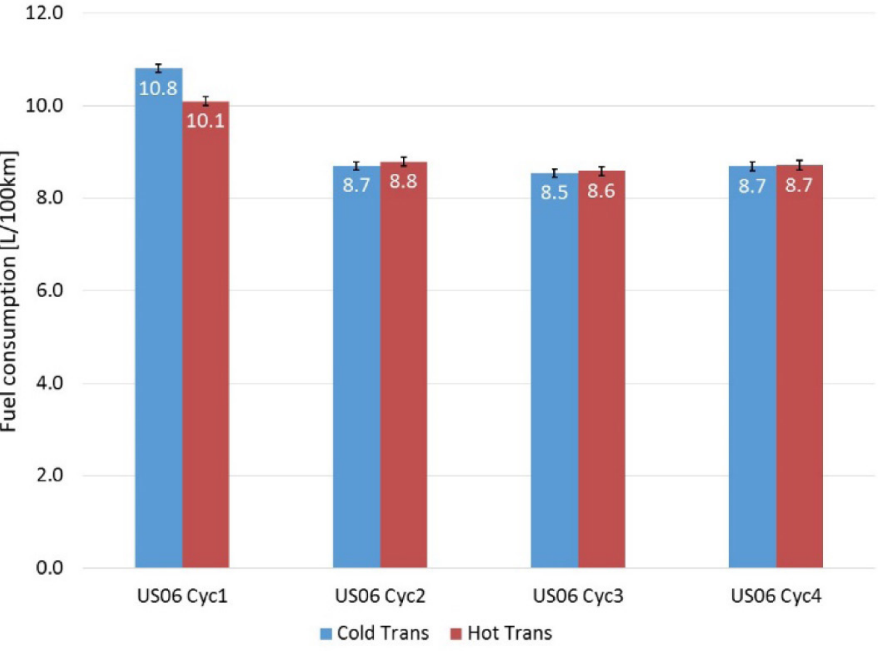

Figure 26. Fuel consumption for back-to-back US06 cycles with transmission pre-warming on and off, $-7^{\circ} \mathrm{C}$ ambient temperature.



Figure 27. Fuel consumption reduction for back-to-back US06 cycles with transmission pre-warming on, $-7^{\circ} \mathrm{C}$ ambient temperature.



Figure 28. Positive tractive force engine and transmission efficiency, heated vs. cold, US06 cycles $-7^{\circ} \mathrm{C}$ ambient temperature.

\section{Ford Fusion Simplified Model}

To determine transmission warm up benefits the simplified thermally sensitive transmission model was benchmarked against dynamometer testing results. The model was then applied to other drive cycles in 
order to investigate the impacts of transmission warming. Figure 29 shows the modeled baseline transmission warmup curve compared to the modeled warmup curve with transmission warming over two UDDS cycles. Due to the Fusion modeling effort preceding Taurus testing, a warmup curve was based on transmission fluid temperature deltas observed from APRF testing of a 2015 Dodge Ram 1500 equipped with active transmission warming. Understanding these were different powertrains and systems with potentially different impacts, these data were what was available at the time of simulation.

Figures 30 and $\underline{31}$ display transmission gear efficiency as a function of lubricant temperature and model predicted gear relative to the measured gear over a portion of the UDDS drive cycle (first and second gear weren't included for reference in Figure 30 as both the amount of time spent in those gears and the amount of torque convertor slip had little impact on results, although the models exist).



Figure 29. FTP UDDS $x 2$ transmission modeling warmup profile, $+22^{\circ} \mathrm{C}$ simulated ambient temperature.
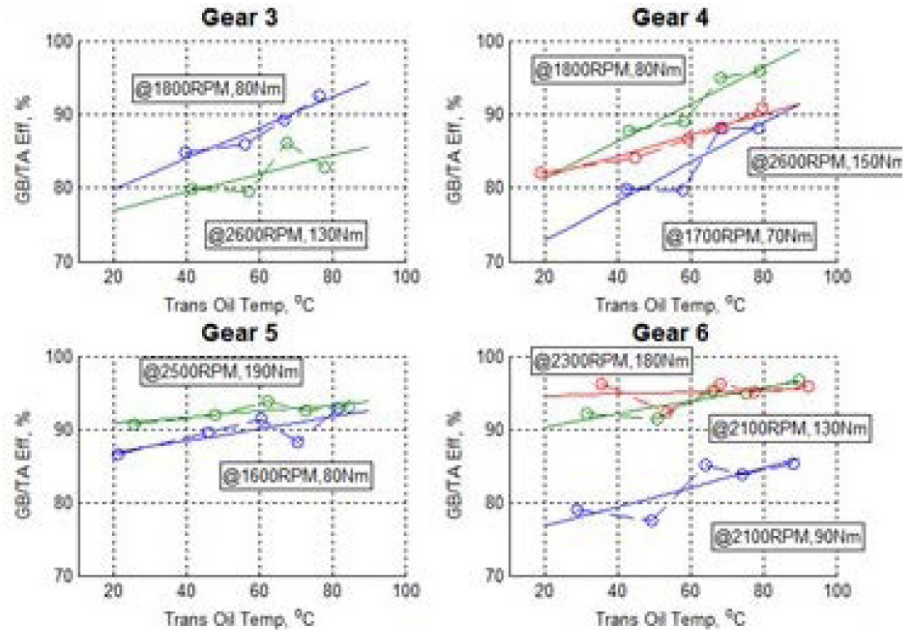

Figure 30. Ford Fusion thermally sensitive simplified transmission model, gear efficiency as a function of lubricant temperature.

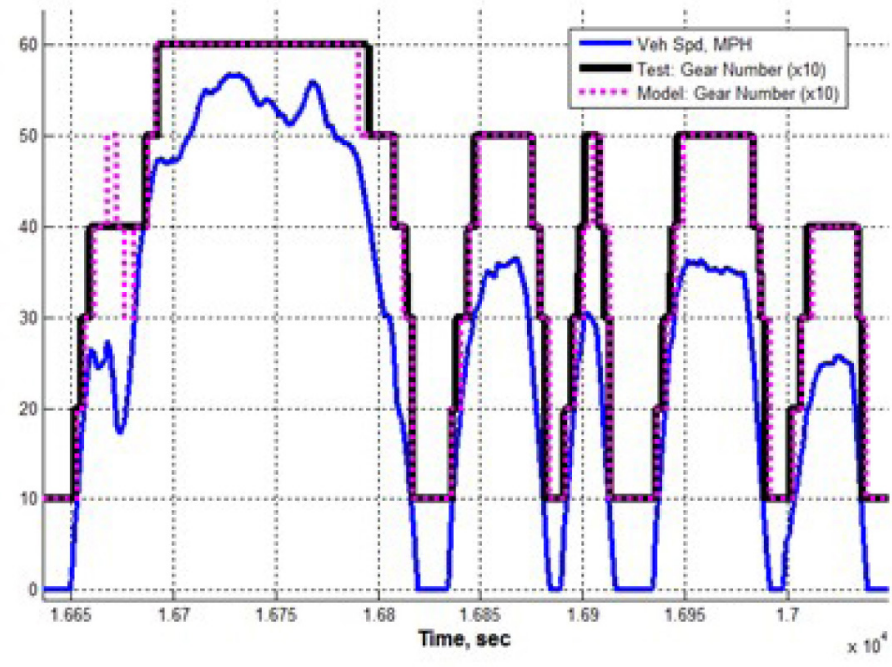

Figure 31. Thermally sensitive simplified transmission model, predictive gear use vs. actually recorded use.

The thermally sensitive model was used predict the Fusion fuel consumption for a series of certification drive cycles over various ambient and transmission starting temperatures and compared to experimental results as shown in Figure 32. The model was shown to predict absolute fuel consumption with a maximum error of $2.6 \%$ relative to the experimental test results. More importantly it was able to accurately predict the fuel consumption benefit for the cases of pre-heated versus cold transmission. One standard deviation error bars were included to reference meaningful changes in fuel consumption relative to variations of the transmission thermal state. Since the predicted fuel consumption benefits from the model were determined to correlate well with experimental data, the model was used to simulate the fuel consumption for a broad range of drive cycles with and without active transmission warming. The absolute fuel consumption results of these simulations, including individual drive cycles and the EPA two- and five-cycle tests, are shown in Figure 33. The fuel consumption benefits are presented in Figure 34.
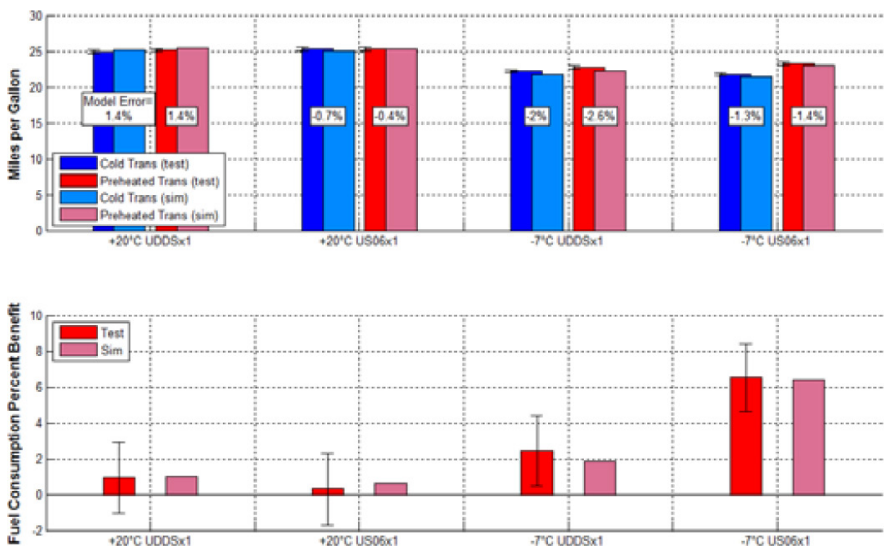

Figure 32. Ford Fusion thermally sensitive simplified transmission model fuel consumption predictions relative to dynamometer testing results. 


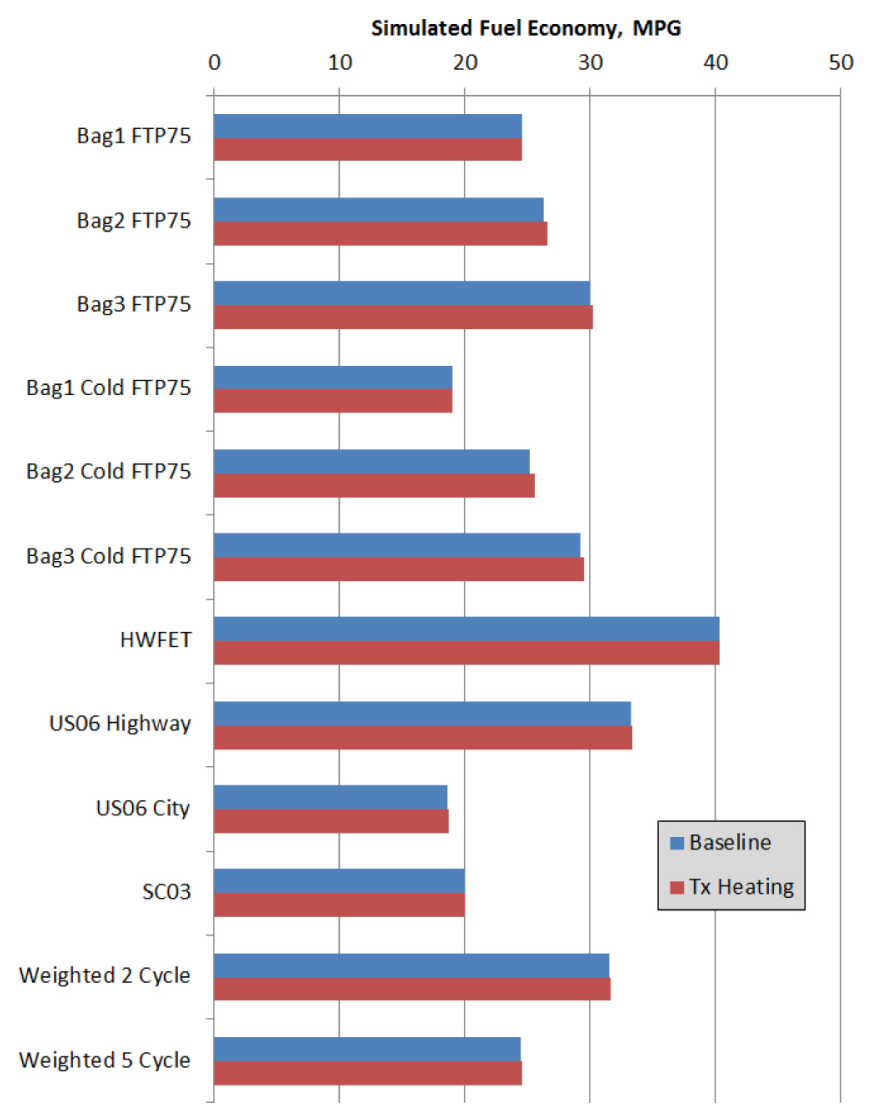

Figure 33. Ford Fusion thermally sensitive simplified transmission model fuel consumption predictions over a wide range of drive cycles, transmission pre-warming on and off.

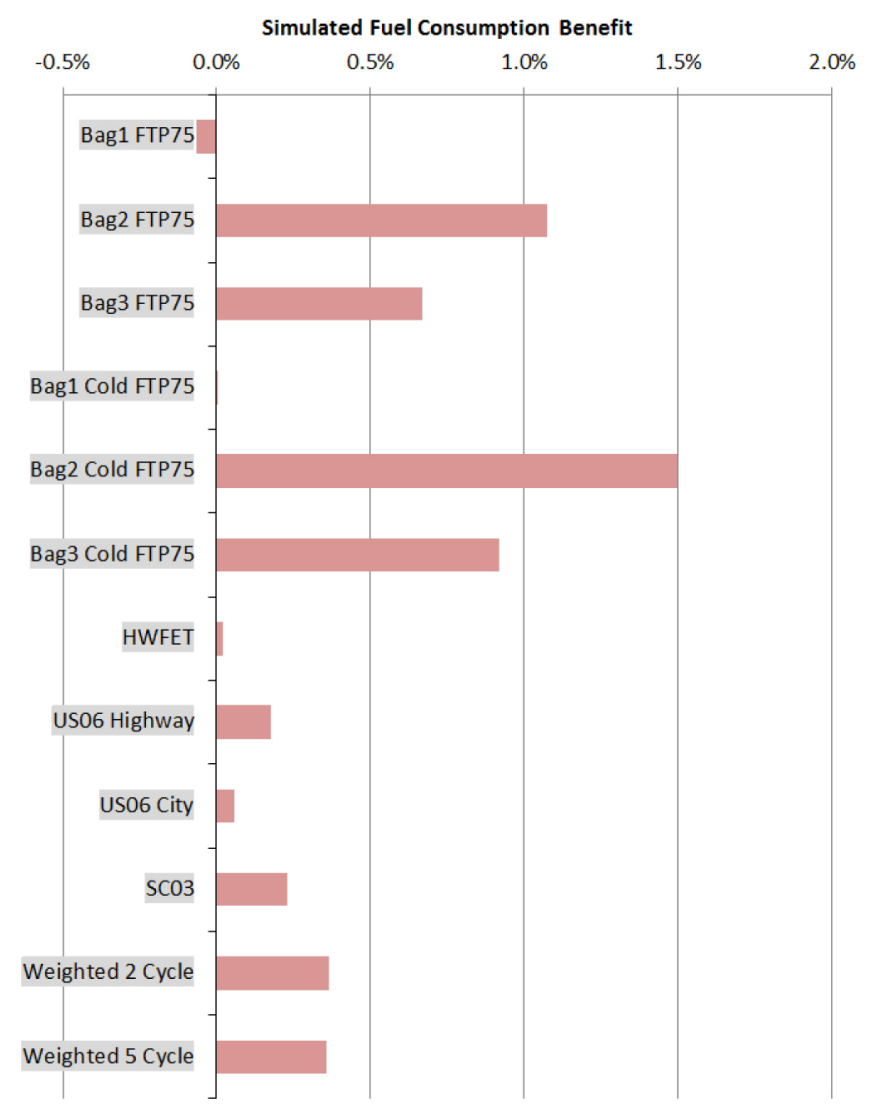

Figure 34. Ford Fusion thermally sensitive simplified transmission model simulated fuel consumption benefit over a wide range of drive cycles, transmission pre-warming on.
These results show that improvements in fuel consumption due to active transmission warming range from negligible up to $1.5 \%$. For bag 1 results of the cold FTP cycle, no benefit is seen as engine coolant temperatures have not been warmed sufficiently for the thermostat to open and warm the transmission fluid. Past that point, transmission warming is active and the benefit realized. The aggressive US06 cycle did not show benefits as large as those of the FTP, nor did the HWY cycle, which contains little transient transmission operation and large amounts of torque convertor lockup. This shows that benefits in the real world will depend upon both climate and driving style.

To evaluate real world effects such as drive cycle intensity, dwell time distributions, and ambient conditions, the simplified Fusion model was simulated over a large set of real world drive cycles using an array of ambient temperatures. Over one million miles of real world drive cycle data was sourced from the National Renewable Energy Laboratory's Transportation Secure Data Center [10] from dozens of U.S. cities and used to evaluate the Fusion model with and without a hypothetical active transmission warming system.

Simulations were conducted for ambient temperatures from $-20^{\circ} \mathrm{C}$ to $+40^{\circ} \mathrm{C}$. An example of modeled results for engine oil, engine coolant, and transmission oil temperatures are shown in Figure 35 as simulated over a four hour sample of real world driving.

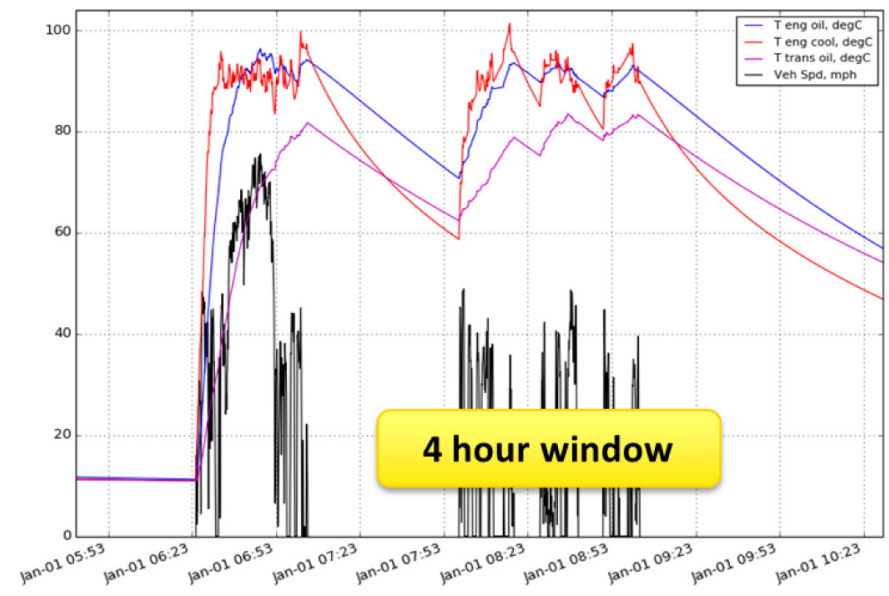

Figure 35. Four hour snapshot of baseline Fusion model simulated over real world driving profile.

Fuel economy results from the Fusion model were tabulated at each ambient temperature with and without active transmission warming enabled. Results can be found in Figure 36. Simulated real world fuel economy over this range of ambient temperatures was found to vary between approximately 27 and 33 miles per gallon (accessory loads from cabin air conditioning were not included in these simulations). In terms of energy benefits, fuel consumption was found to decrease between $0.45 \%$ and $0.71 \%$ as a result of active transmission warming (dependent on ambient temperature). Using EPA estimates of VMT by ambient temperature (shown in Figure 2) an average real world benefit of $0.50 \%$ is calculated. 


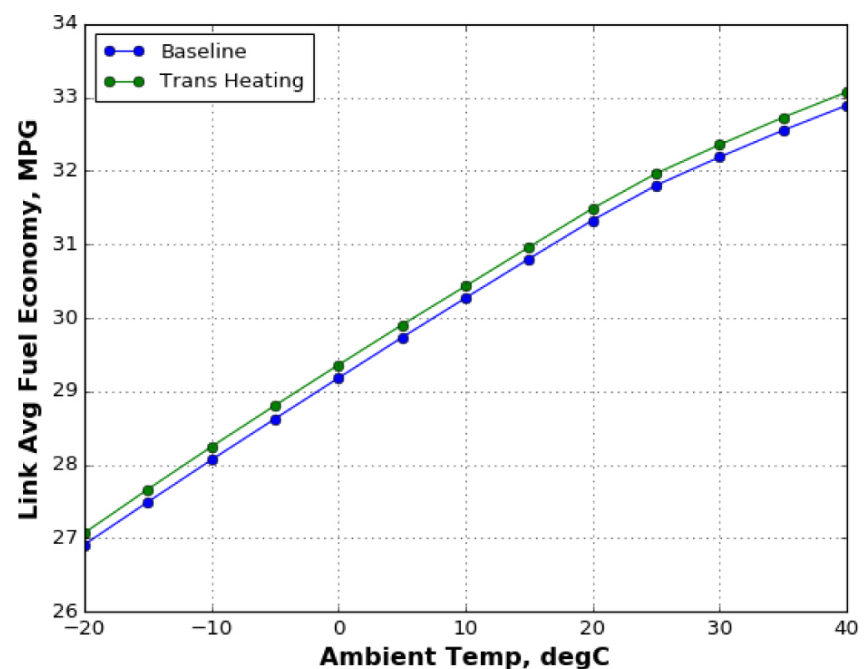

Figure 36. Simulated fuel economy of simplified Fusion model evaluated with and without transmission warming as a function of ambient temperature.

Recall from Figure 34 that the simulated 5-cycle benefit of this modeled transmission warming system was $0.36 \%$. The delta between the $0.50 \%$ simulated real world benefit and the $0.36 \%$ simulated on-cycle benefit results in a $0.14 \%$ estimated off-cycle credit. While the estimated off-cycle credit in this analysis was found to fall below the existing EPA off-cycle credit of $0.58 \%$ for active transmission warming systems, several sources of uncertainty prevent any definitive conclusions from being made regarding the efficacy of the existing off-cycle credit. Due to the Fusion modeling effort preceding Taurus testing, a hypothetical warmup curve was based on available transmission fluid temperature deltas observed testing a 2015 Dodge Ram 1500 equipped with active transmission warming. This warming curve was less than the Taurus which reduced the modeled benefit. Secondly, the Fusion model represents a hypothetical transmission warming system overlaid on a single transmission. In practice variable benefits from different transmission warming systems depend on design (conventional, CVT, etc.), implementation, and control strategy. Finally, the benefits being assessed are of similar magnitude to the testing repeatability and model accuracy values presented in this work which prevents relatively small discrepancies from being considered statistically significant. Additional testing and modeling of various transmission warming technologies and warming strategy implementations would be required to make definitive conclusions regarding the efficacy of the existing off-cycle credit.

\section{Conclusions}

Chassis dynamometer testing and thermally sensitive simplified modeling analysis was used to better understand the impacts of transmission warming technology on fuel consumption. In this work, a 2013 Ford Taurus was tested over various drive cycles and temperatures with the transmission heater enabled and disabled in order to experimentally quantify the fuel consumption benefits of active transmission warming. Furthermore, a heavily instrumented 2011 Ford Fusion was used to develop a model for deeper investigations.
Dynamometer testing of the Ford Taurus over UDDS cycles at $+22^{\circ} \mathrm{C}$ showed an approximate $1.4 \%$ reduction in fuel consumption for the first cold start cycle with this benefit reducing over the following three cycles. This reduction in consumption was shown to be statistically significant in which repeat tests were shown to measure fuel consumption within $0.5 \%$ repeatability. Per the Ford Fusion, pre-warming vs. cold start transmission testing showed definitive benefits over $-7^{\circ} \mathrm{C}$ ambient UDDS and US06 cycles. By pre-warming the transmission by approximately $25^{\circ} \mathrm{C}$, the UDDS fuel consumption improved $2.5 \%$ whereas the US06 improved $7.0 \%$. However, since pre-warming of the transmission also lead to an increase in the initial temperature of the engine oil, integrated efficiencies of the engine and transmission were compared over the cycles to separate out engine from transmission effects. Positive tractive effort energies integrated over the cycle showed a $5.5 \%$ and $1.1 \%$ improvement in transmission efficiency over the first UDDS and US06 cycles at $-7^{\circ} \mathrm{C}$ ambient temperature by pre-warming the transmission. Additionally engine efficiencies were shown to decrease $2.1 \%$ for the UDDS cycle and increase $4.6 \%$ for the US06 cycle by pre-warming the system. The decrease in efficiency for a slightly warmed engine oil relative to the cold start is suggested to be caused by slightly reduced pumping losses in the cold start case in which vehicle system energy requirements are higher, resulting in higher engine loads (even though more fuel is consumed in the cold start case, the reduced pumping losses act to increase the integrated engine efficiency).

Finally, the thermally sensitive transmission efficiency model was shown to predict absolute fuel consumption for a wide range of drive cycles and ambient temperatures with a maximum error of $2.6 \%$ relative to the experimental test results. Applying the model to a number of drive cycles and ambient temperatures showed simulated fuel consumption benefits due to active transmission warming ranging from negligible to $1.5 \%$ depending upon the cycle and temperature. The high end of these benefits is in good agreement with the estimations provided by the previous work as discussed in the Introduction.

\section{References}

1. The White House, Office of the Press Secretary, "Obama Administration Finalizes Historic 54.5 MPG Fuel Efficiency Standards," http://www.whitehouse.gov/the-pressoffice/2012/08/28/obama-administration-finalizes-historic-545mpg-fuel-efficiency-standard

2. U.S. Federal Register, Environmental Protection Agency, Department of Transportation, National Highway Traffic Safety Administration “2017 and Later Model Year Light-Duty Vehicle Greenhouse Gas Emissions and Corporate Average Fuel consumption Standards; Final Rule," http://www.gpo.gov/fdsys/ pkg/FR-2012-10-15/pdf/2012-21972.pdf

3. U.S. Department of Energy and U.S. Environmental Protection Agency "Fuel consumption Tests: Detailed Test Information," http://www.fueleconomy.gov/feg/fe test_schedules.shtml

4. U.S. EPA \& NHTSA Joint Technical Support Document "Final Rulemaking for 2017-2025 Light-Duty Vehicle Greenhouse Gas Emission Standards and Corporate Average Fuel consumption Standards" https://www3.epa.gov/otaq/climate/ documents/420r12901.pdf 
5. Jehlik, F., Wood, E., Gonder, J., and Lopp, S., "Simulated RealWorld Energy Impacts of a Thermally Sensitive Powertrain Considering Viscous Losses and Enrichment," SAE Int. J. Mater. Manf. 8(2):239-250, 2015, doi:10.4271/2015-01-0342.

6. Jehlik, F., "Methodology and Analysis of Determining Plug-In Hybrid Engine Thermal State and Resulting Efficiency," SAE Technical Paper 2009-01-1308, 2009, doi: 10.4271/2009-011308 .

7. Jehlik F., and Rask E., , "Development of Variable Temperature Brake Specific Fuel Consumption Engine Maps," SAE Technical Paper 2010-01-2181, 2010, doi:10.4271/2010-012181.

8. Jehlik, F., Rask, E., and Duoba, M., "Real-World Thermal Effects on Wheel Assembly Efficiency of Conventional and Electric Vehicles," SAE Int. J. Passeng. Cars - Mech. Syst.9(1):25-35, 2016, doi:10.4271/2016-01-0236.

9. Argonne National Laboratory, Transportation Technology R\&D Center "Advanced Powertrain Research Facility (APRF)," http://www.anl.gov/energy-systems/facilities/advancedpowertrain-research-facility

10. “Transportation Secure Data Center." (2016). National Renewable Energy Laboratory. Accessed October 1, 2016: www.nrel.gov/tsdc.

11. National Renewable Energy Laboratory, "National Solar Radiation Database, Typical Meteorological Year Database 3," Golden, CO, http://rredc.nrel.gov/solar/old_data/ nsrdb/1991-2005/tmy3/

12. Ostrouchov, N., "Effect of Cold Weather on Motor Vehicle Emissions and Fuel consumption," SAE Technical Paper 780084, 1978, http://papers.sae.org/780084/

13. Andrews, G., Harris, J., and Ounzain, A., "SI Engine WarmUp: Water and Lubricating Oil Temperature Influences," SAE Technical Paper 892103, 1989, doi:10.4271/892103.

14. Andrews, G.E., Harris, J.R., and Ounzain, A., "Experimental Methods for Investigating the Transient Warming and Emissions of an SI Engine during the Warm-Up Period," in: Experimental Methods in Engine Research and Development, IMechE, pp. 101-108, 1988.

15. Andrews, G., Ounzain, A., Li, H., Bell, M. ., "The Use of a Water/Lube Oil Heat Exchanger and Enhanced Cooling Water Heating to Increase Water and Lube Oil Heating Rates in Passenger Cars for Reduced Fuel Consumption and CO2 Emissions During Cold Start.," SAE Technical Paper 2007-012067, 2007, doi:10.4271/2007-01-2067.

16. Carlson, R., Duoba, M., Bocci, D., and Lohse-Busch, H., "OnRoad Evaluation of Advanced Hybrid Electric Vehicles Over a Wide Range of Ambient Temperatures," Paper \#275, EVS23, 2007,http://www.afdc.energy.gov/pdfs/impact battery_phev.pdf

17. Carlson, R., Christenson, M., and Shinomiya, R., "Influence of Sub-Freezing Conditions on Fuel Consumption and Emissions of Two Plug-In Hybrid Electric Vehicles," EVS-24, Paper \#2760135, 2009.
18. Kunze, K., Wolff, S., Lade, I., and Tonhauser, J., “A Systematic Analysis of CO2-Reduction by an Optimized Heat Supply during Vehicle Warm-up," SAE Technical Paper 2006-01-1450, 2006, doi: $10.4271 / 2006-01-1450$.

19. Myers, R.H., and Montgomery, D.C., "Response Surface Methodology: Process and Product Optimization Using Designed Experiment,"Wiley-Interscience, 1995.

\section{Contact Information}

Advanced Powertrain Research Facility

Argonne National Laboratory

Energy Systems Division

9700 S. Cass Ave.

Argonne, IL 60439

Forrest Jehlik

(630) 252-6403

fjehlik@anl.gov

Simeon Iliev

(630) 252-3825

iliev@anl.gov

Transportation and Hydrogen Systems Center

National Renewable Energy Laboratory

15013 Denver West Pkwy MS 1634

Golden, CO 80401

Eric Wood

(303) 275-3290

eric.wood@nrel.gov

\section{Acknowledgments}

This study was supported by the U.S. Department of Energy's Vehicle Technologies Office. The authors would specifically like to thank David Anderson for his guidance.

Use of Argonne National Laboratory's Advanced Powertrain Research Facility (developed under funding from the U.S.

Department of Energy's Vehicle Technologies Office) was utilized in the completion of this study.

\section{Definitions/Abbreviations}

4WD - Four Wheel Drive

Bag1/Bag2/Bag3/Bag4 - Emission bags for EPA certification testing. Also used to denote cycle/portion of cycle.

${ }^{\circ} \mathrm{C}$ - Degrees centigrade

CVT - Continuous Variable Transmission

APRF - Advanced Powertrain Research Facility (Argonne)

Argonne - Argonne National Laboratory

Eng - Engine

EPA - U.S. Environmental Protection Agency

FTP75 - EPA Federal Test Procedure drive cycle sequence

GB/TA - Gearbox/Transmission 
HWFET - EPA certified highway fuel economy test

Nm - Newton-meters (torque)

OEM - Original Equipment Manufacturer

SC03 - EPA Supplemental Federal Test Procedures

Trans - Transmission

TMY - Typical Meteorological Year

UDDS - Urban Dynamometer Driving Schedule (EPA defined)

US06 - US06 dynamometer driving schedule (EPA defined)

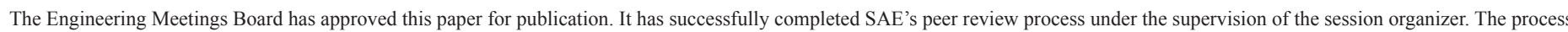
requires a minimum of three (3) reviews by industry experts.


otherwise, without the prior written permission of SAE International.

Positions and opinions advanced in this paper are those of the author(s) and not necessarily those of SAE International. The author is solely responsible for the content of the paper.

ISSN 0148-7191

http://papers.sae.org/2017-01-0157 